\title{
THE EFFECT OF PIMOZIDE, A DOPAMINE ANTAGONIST, ON PITUITARY GONADOTROPHIC FUNCTION IN THE RAT
}

\author{
S. A. R. CHOUDHURY, * R. M. SHARPE AND P. S. BROWN \\ Department of Pharmacology, The Medical School, University Walk, Bristol BS8 1TD
}

(Received 18th fuly 1973)

\begin{abstract}
Summary. Injection of pimozide reduced compensatory ovarian hypertrophy and raised pituitary $\mathbf{L H}$ content in hemispayed cyclic and androgenized female rats. Pimozide inhibited spontaneous and induced ovulation and markedly reduced the rise in serum $\mathrm{LH}$ during the afternoon of pro-oestrus. Pimozide failed to reduce serum $\mathrm{LH}$ in male rats and caused no apparent delay in sexual maturation in males or females. The results suggest that the drug suppresses the ovulatory release of $\mathrm{LH}$, presumably by antagonizing hypothalamic dopamine. The drug appears to have less striking effects on the tonic secretion of FSH and LH.
\end{abstract}

\section{INTRODUCTION}

The involvement of dopamine in the hypothalamic control of gonadotrophin secretion seems well established (see e.g. McCann \& co-authors, 1972) but there are still conflicting views about its precise rôle (e.g. Hökfelt \& Fuxe, 1972). We have used pimozide, a centrally acting dopamine antagonist (Andén, Butcher, Corrodi, Fuxe \& Ungerstedt, 1970), and have obtained results which support the idea that dopaminergic mechanisms are excitatory in FSH secretion (Choudhury, Sharpe \& Brown, 1973).

The present paper describes the effect of pimozide on gonadotrophic function in male and female rats in a variety of different experimental situations. Pimozide may act at a number of different sites, and the use of a variety of different experimental situations has the advantage that, if a consistent endocrinological effect is found, it is unlikely to be due to a purely accidental phenomenon associated with a particular test.

\section{MATERIALS AND METHODS}

Animals and drug treatment

Porton rats from our closed colony were injected subcutaneously with pimozide (Janssen Pharmaceuticals) which, in most experiments, was sus-

* Commonwealth Medical Scholar from Bangladesh. 
pended in $0.9 \% \mathrm{NaCl}$ containing $0.25 \%$ methylcellulose. In experiments in which plasma levels of $\mathrm{LH}$ were measured or in which rats were examined for ovulation, the pimozide was dissolved by grinding with a glass rod moistened with acetic acid and this solution was then diluted with isotonic $\mathrm{NaCl}$ or dextrose solution. In all experiments, control animals were injected with the vehicle.

Castration and sampling of blood were performed under ether anaesthesia. When animals were killed, the pituitaries were removed, pooled within treatment groups, and homogenized as described previously (Fawke \& Brown, 1970). The ovaries and uteri were weighed fresh while the testes, seminal vesicles and ventral prostates were weighed after fixation in formol-saline.

In one experiment, adult male rats (of approximately $300 \mathrm{~g}$ body weight), were castrated and injected with $10 \mathrm{mg}$ testosterone esters (Sustanon 250, Organon) before receiving five daily doses of pimozide to study its effect on pituitary FSH content (Brown \& Fawke, 1972).

\section{Assays of gonadotrophin}

Assays of FSH in pituitary homogenates were carried out by a modification of the method of Steelman \& Pohley (1953), as described previously (Fawke \& Brown, 1970). The LH content of pituitary homogenates or of rat sera was measured by a double antibody radioimmunoassay using materials supplied in NIAMD kits. When sera from adult male rats were assayed, measurable effects were only obtained with the highest concentration which could be used. These sera were, therefore, tested at this dose level only against a dose-response curve for NIAMD-rat-LH-RP1, all sera from one experiment being assayed simultaneously. In all other cases, multiple dose levels were used and direct comparisons were made between sera or homogenates from pimozide- and vehicle-treated rats. The response, measured as the percentage radioactivity bound, was transformed to logits to obtain linearity, and a restricted portion of the $\log$ dose-response line was used to avoid heterogeneity of variance. The results could then be computed as parallel-line assays and relative potencies are shown in the Tables accompanied by $95 \%$ fiducial limits as in the bioassay.

\section{Pimozide and ovulation}

Spontaneous ovulation. Vaginal smears from adult female rats were examined daily and animals that displayed two consecutive 4-day cycles were used. On the pro-oestrous day of the next cycle, pimozide or its vehicle was injected at 10.00 hours colony time (i.e. $10 \mathrm{hr}$ after the midpoint of a 12 -hr dark period). Next morning, the oviducts were examined for fresh ova by a person unaware of the treatment which individual rats had received.

Induced ovulation. Female rats, aged 25 days, were injected at 11.00 hours colony time with 20 or 40 i.u. PMSG (Folligon, Intervet) in $0.5 \mathrm{ml}$ of $0.9 \%$ $\mathrm{NaCl}$. Pimozide or its vehicle was injected at 10.00 hours when the rats were 27 days old. The animals were killed $24 \mathrm{hr}$ later, i.e. $71 \mathrm{hr}$ after the injection of PMSG, and the oviducts were examined for freshly ovulated ova as described above. 


\section{Pimozide and compensatory ovarian hypertrophy}

The effect of pimozide was tested on normal and androgenized female rats. The latter were prepared by the subcutaneous injection of $1.25 \mathrm{mg}$ testosterone propionate into female rats on the 5th day of life. At the same time, control rats were injected with oily vehicle alone and are referred to as 'oil-treated'. Daily vaginal smears were started when the rats were 100 to 120 days old. Hemispaying was performed under ether anaesthesia when oil-treated rats were in oestrus, after showing two consecutive 4-day cycles, or when androgen-treated rats had shown an oestrous smear for 8 consecutive days. The right ovary was removed and weighed (first ovarian weight, OW1) and the body weight was measured at the time of operation (BW1).

Pimozide or its vehicle were injected daily, between 09.30 and 10.30 hours, for 7 days starting on the day of operation and the rats were killed $72 \mathrm{hr}$ after the final injection. The left ovary was removed, cleaned and weighed (OW2), and fixed for sectioning: the final body weight (BW2) was noted. The measure of ovarian hypertrophy used for computations was (log OW2-log OW1). The logarithmic transformation was adopted because the hypertrophy shown by the small ovaries of androgenized rats was absolutely smaller than that shown by the larger ovaries of normal animals, but proportionally similar. As it was intended to compare the responses of androgen- and oil-treated rats, it seemed appropriate to use an index of hypertrophy which reflected the proportional similarity.

The ovaries removed at the end of the experiment were sectioned serially at $10 \mu \mathrm{m}$ and every tenth section was stained and examined. In androgentreated rats, the three largest follicles were selected from each ovary and their maximum diameter (from the junction of theca interna and membrana granulosa) was measured as a mean of two diameters at right angles to each other. The mean of these three values for the three largest follicles was taken as the index of follicular size for each ovary. In the oil-treated rats, the number of corpora lutea exceeding $0.86 \mathrm{~mm}$ in diameter was counted in each ovary.

\section{RESULTS}

\section{Effect of pimozide on intact maturing male and female rats}

Two groups of male rats, aged 42 and 62 days respectively at the start of the experiment, were treated with pimozide daily for 8 consecutive days. In neither group did this treatment cause a significant change in the weight of the testis, anterior pituitary or secondary sex organs (Table 1), despite the fact that pimozide caused a significantly lower final body weight in the older rats. In the younger animals, treatment caused a doubling of pituitary FSH content which was statistically significant (Table 2). In the older group, pimozide did not alter pituitary FSH or LH levels.

Treatment of intact female rats, aged 34 days, with five daily doses of pimozide failed to produce any significant change in final body weight or in that of the ovaries and uterus (Table 1$)$. The higher dose $(0.2 \mathrm{mg}$ /day) caused a small but statistically significant increase in the pituitary content of immunoreactive LH (Table 2). 


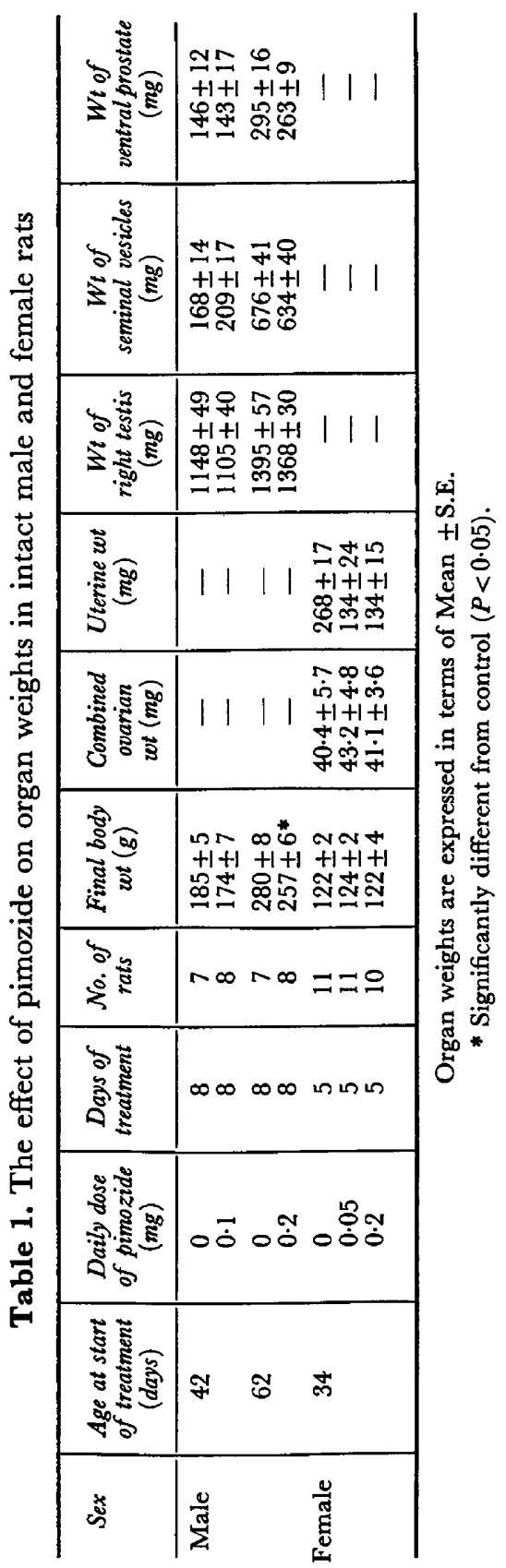


Pituitary FSH content in castrated, testosterone-treated male rats

Treatment of castrated, testosterone-treated rats for 5 days with pimozide $(0.2$ or $0.4 \mathrm{mg} /$ day) produced no significant change in body or anterior pituitary weight when the animals were killed $24 \mathrm{hr}$ after the fifth injection of drug. The pituitary FSH content was not significantly altered (Table 2).

Table 2. Effect of pimozide on the pituitary gonadotrophin content of intact and treated male and female rats

\begin{tabular}{|c|c|c|c|c|}
\hline \multirow[t]{2}{*}{ Type of rat } & \multirow[t]{2}{*}{$\begin{array}{c}\text { Dose of } \\
\text { pimozide } \\
\text { (mg/day) }\end{array}$} & \multirow[t]{2}{*}{$\begin{array}{l}\text { Days of } \\
\text { treatment }\end{array}$} & \multicolumn{2}{|c|}{$\begin{array}{l}\text { Pituitary gonadotrophin content in drug- } \\
\text { treated rats as } \% \text { of that in vehicle- } \\
\text { treated rats }(95 \% \text { fiducial limits })\end{array}$} \\
\hline & & & $F S H$ & $L H$ \\
\hline Male: 42 days old* & $0 \cdot 1$ & 8 & 213 (133 to 342$)$ & - \\
\hline Male: 62 days old* & 0.2 & 8 & $108(66$ to 176$)$ & 95 (78 to 115$)$ \\
\hline $\begin{array}{l}\text { Male: castrated } \\
\text { testosterone-treated }\end{array}$ & $\begin{array}{l}0.2 \\
0.4\end{array}$ & $\begin{array}{l}5 \\
5\end{array}$ & $\begin{array}{l}102(70 \text { to } 147) \\
132(90 \text { to } 193)\end{array}$ & 二 \\
\hline Female: 34 days old* & $\begin{array}{l}0.05 \\
0.2\end{array}$ & $\begin{array}{l}5 \\
5\end{array}$ & 二 & $\begin{array}{l}95(80 \text { to } 112) \\
136(115 \text { to } 159)\end{array}$ \\
\hline \multirow[t]{2}{*}{ Female: hemispayed } & $\begin{array}{l}0.2 \\
0.8\end{array}$ & $\begin{array}{l}7 \\
7\end{array}$ & 二 & $\begin{array}{l}112(78 \text { to } 160) \\
285(198 \text { to } 408)\end{array}$ \\
\hline & $\begin{array}{l}0.2 \\
0.8\end{array}$ & $\begin{array}{l}7 \\
7\end{array}$ & - & $\begin{array}{l}262(244 \text { to } 280) \\
278(260 \text { to } 296)\end{array}$ \\
\hline $\begin{array}{l}\text { Female: androgenized } \\
\text { hemispayed }\end{array}$ & $\begin{array}{l}0.2 \\
0.8\end{array}$ & $\begin{array}{l}7 \\
7\end{array}$ & $\begin{array}{l}109(56 \text { to } 220) \\
129(66 \text { to } 250)\end{array}$ & $\begin{array}{l}136(124 \text { to } 148) \\
146(133 \text { to } 159)\end{array}$ \\
\hline
\end{tabular}

Table 3. Effect of pimozide on ovulation induced by PMSG in rats

\begin{tabular}{c|c|c}
\hline \multirow{2}{*}{ Dose of pimozide (mg) } & \multicolumn{2}{|c}{ Number of animals ovulating/total number } \\
\cline { 2 - 3 } & 40 i.u. PMSG & 20 i.u. PMSG \\
\hline 0 & $10 / 10$ & $7 / 10$ \\
0.4 & $4 / 8^{*}$ & $1 / 8^{*}$ \\
\hline
\end{tabular}

* Significant reduction $(P<0.05)$ compared with vehicletreated rats receiving the same dose of PMSG (Fisher's exact test).

\section{Effect of pimozide on ovulation}

Spontaneous ovulation. Pimozide injected on the day of pro-oestrus decreased the number of rats ovulating. Rats injected with the vehicle all ovulated (eight out of eight) but a dose of $0.8 \mathrm{mg}$ pimozide significantly reduced the number ovulating to two out of eight $(P<0.01$ : Fisher's exact test). A larger dose of pimozide $(2 \mathrm{mg})$ reduced ovulation less strikingly to five out of eight.

Induced ovulation. Pimozide in a dose of $0.4 \mathrm{mg}$ significantly $(P<0.05)$ reduced the percentage of animals which ovulated in response to both doses of PMSG (Table 3). 


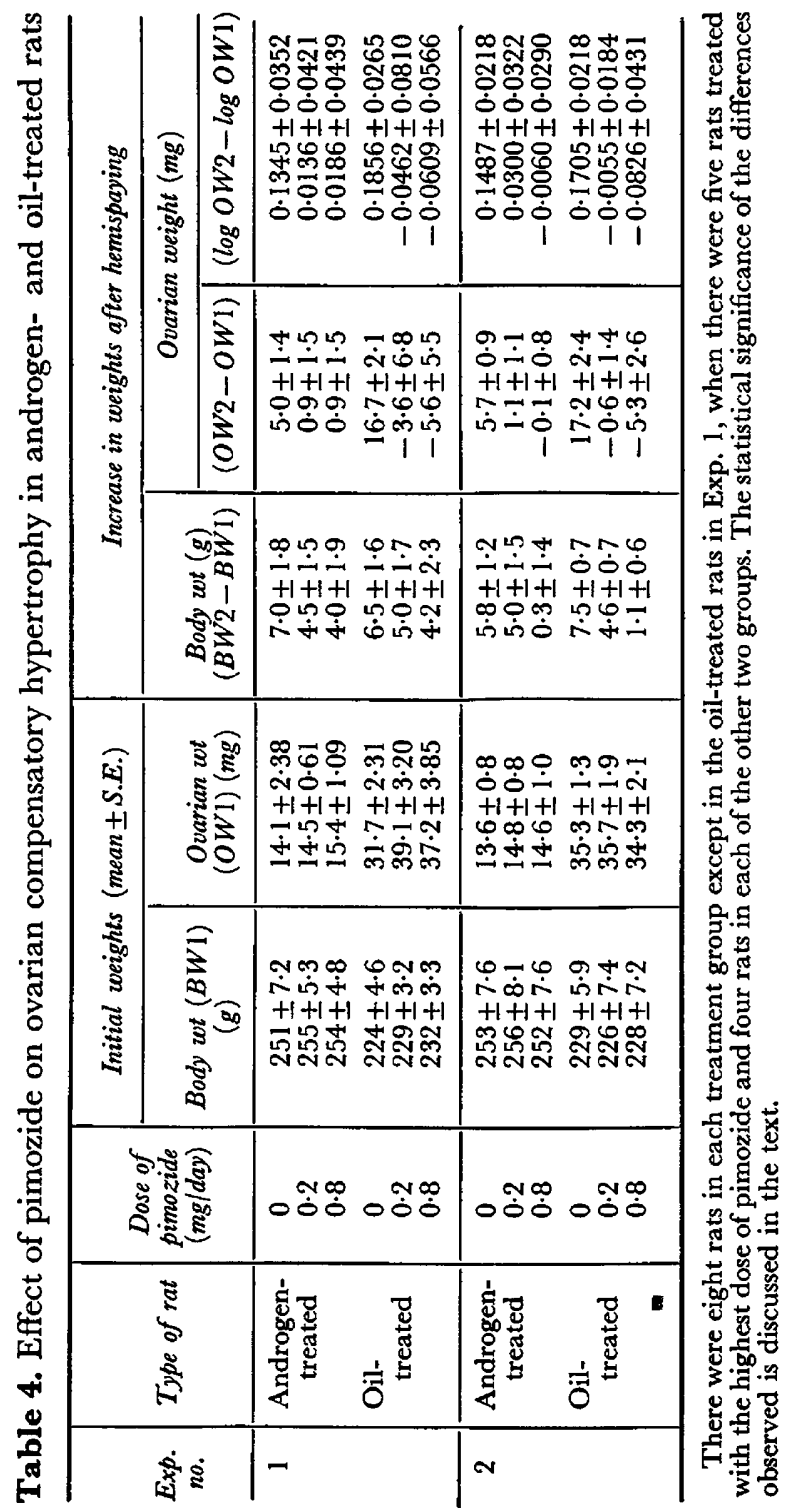


Pimozide and compensatory ovarian hypertrophy

In two experiments (Table 4), pimozide consistently reduced ovarian compensatory hypertrophy. In the first experiment, analyses of variance (done separately on the data for the two types of rats) showed that the effect of pimozide was significant in the oil-treated rats $(P<0.05)$ but not in the androgentreated rats. In the second experiment, the numbers of the two types of rats were equal and the data were analysed together. This showed the overall effect of pimozide to be highly significant $(P<0.01)$. The inhibitory effect of the drug was more pronounced in the oil-treated rats, as it had been in the first experiment, but the difference in response of the two types of rat was not significant (interaction: effect of pimozide/type of rat: $F=1 \cdot 16$; d.f. $2 / 23$ ). Treatment with pimozide also reduced gain in body weight; this was significant $(P<0.01)$ in the second experiment.

Follicular diameter was measured in the ovaries of the androgen-treated rats in the second experiment. Pimozide reduced the mean diameter of the three largest follicles but not significantly $(0 \cdot 1>P>0 \cdot 05)$. In the oil-treated animals in the same experiment, the mean number of corpora lutea of diameter $>0.86$ $\mathrm{mm}$ was as follows: eight ovaries from vehicle-treated rats-mean $6.6 \mathrm{~mm}$ (range 4 to $12 \mathrm{~mm}$ ); seven ovaries from rats receiving the lower dose of pimozide-1.8 ( 1 to 4$)$; eight ovaries from rats receiving the higher dose$2 \cdot 6(0$ to 4$)$.

\section{Pituitary gonadotrophin content in hemispayed rats}

Pituitary LH was measured in the hemispayed oil-treated rats at the end of both experiments on compensatory ovarian hypertrophy. In both instances, the higher dose of pimozide caused a striking and significant increase in LH content (Table 2). Both FSH and LH were measured in pituitary homogenates from hemispayed androgen-treated rats, pooled from the two experiments. In these animals, pimozide caused no significant change in FSH and only a small, but significant, increase in LH content (Table 2).

\section{Effect of pimozide on serum $\mathrm{LH}$}

Adult male rats were handled daily for a week to accustom them to disturbance and then injected at 08.00 hours with $0.4 \mathrm{mg}$ pimozide or its vehicle. Three pimozide-treated and three vehicle-treated rats were killed $1 \frac{1}{2}, 3$ and $6 \mathrm{hr}$ after the injection and serum samples were taken. The sera were assayed, at one dose level only, and the mean $( \pm$ S.E.) serum LH (ng NIAMD-rat-LH$\mathrm{RP} 1 / \mathrm{ml}$ ) in the vehicle-treated and pimozide-treated rats (in that order) in the various treatment-groups was as follows: $1 \frac{1}{2} \mathrm{hr}: 44 \pm 5 \cdot 5,50 \pm 2 \cdot 4 ; 3 \mathrm{hr}$ : $42 \pm 8 \cdot 5,47 \pm 5 \cdot 5 ; 6 \mathrm{hr}: 61 \pm 7 \cdot 8,46 \pm 9 \cdot 5$. A second assay on sera pooled from the three rats within each treatment-group showed a similar pattern in which pimozide produced no significant effect.

Adult female rats which had shown two consecutive 4-day cycles were injected with $0.4 \mathrm{mg}$ pimozide or vehicle at 10.00 hours colony time on their next pro-oestrous day. A group of untreated rats was killed at this time to provide baseline values for serum $\mathrm{LH}$, and further groups of vehicle- and drug-treated rats were killed at 15.00 and 17.00 hours. Two separate experiments were 
performed with three or four rats in each of the five treatment groups: sera from the rats in each group were pooled for assay (Table 5). In both experiments, there was a significant rise in serum LH during the afternoon: this was more striking in the second experiment. Treatment with pimozide prevented the rise at 15.00 hours and reduced it significantly at 17.00 hours.

Table 5. Serum LH in pro-oestrous rats treated with pimozide

\begin{tabular}{|c|c|c|c|c|c|}
\hline \multirow[t]{2}{*}{$\begin{array}{l}\text { Exp. } \\
\text { no. }\end{array}$} & \multirow[t]{2}{*}{ Treatment* } & \multicolumn{2}{|c|}{$\begin{array}{c}\text { Serum LH at } 15.00 \text { and } 17.00 \text { hours as } \% \\
\text { of serum LH at } 10.00 \text { hours }(95 \% \text { fiducial } \\
\text { limits })\end{array}$} & \multicolumn{2}{|c|}{$\begin{array}{l}\text { Serum } L H \text { at } 15.00 \text { and } 17.00 \text { hours in pimo- } \\
\text { zide-treated rats as } \% \text { of serum LH in } \\
\text { vehicle-treated rats }(95 \% \text { fiducial limits })\end{array}$} \\
\hline & & 15.00 hours & 17.00 hours & 15.00 hours & 17.00 hours \\
\hline 1 & $\begin{array}{l}\text { Vehicle } \\
\text { Pimozide }\end{array}$ & $\begin{array}{c}208(146 \text { to } 298) \\
88(60 \text { to } 130)\end{array}$ & $\begin{array}{l}346(233 \text { to } 512) \\
240(167 \text { to } 348)\end{array}$ & 27 (19 to 39$)$ & $70(50$ to 96$)$ \\
\hline 2 & $\begin{array}{l}\text { Vehicle } \\
\text { Pimozide }\end{array}$ & $\begin{array}{c}129(106 \text { to } 157) \\
75(62 \text { to } 91)\end{array}$ & $\begin{array}{l}834(620 \text { to } 1120) \\
240(198 \text { to } 290)\end{array}$ & $58(47$ to 71$)$ & 29 (22 to 37$)$ \\
\hline
\end{tabular}

* See text for details.

\section{DISCUSSION}

Pimozide had several effects which may be interpreted as due to suppression of the ovulatory surge of LH secretion. These were (a) the inhibition of ovulation in both situations in which animals were examined for fresh ova, (b) the inhibition of ovarian compensatory hypertrophy with a reduction in the number of corpora lutea in hemispayed cyclic rats, (c) the raised pituitary stores of LH in hemispayed cyclic animals, and (d) the inhibition of the rise in serum LH during the afternoon of pro-oestrus. These results were consistent and sometimes striking. They lend strong support to the hypothesis that dopamine, the central actions of which are specifically blocked by pimozide (Andén et al., 1970), has an excitatory rôle in the ovulatory release of LH. This accords with the views of McCann et al. (1972) and the findings of Kordon \& Glowinski (1969).

The effect of pimozide on the tonic secretion of $\mathrm{LH}$ was less apparent, but this may be due to the greater difficulty of demonstrating an effect on phenomena which are less dramatic than those associated with ovulation. An effect on tonic secretion was looked for in male rats but there was no good evidence that pimozide altered serum LH levels, pituitary LH stores or the growth of androgen-dependent organs. Similarly, as judged by ovarian and uterine weights, pimozide did not significantly inhibit sexual maturation in females at an age when effects of drugs can often be demonstrated (Brown, 1971). These females did, however, show a small increase in pituitary LH stores, which could have been due to inhibition of tonic secretion. As the animals were 39 days old when killed, however, some may have already experienced an ovulatory release of LH, a process which pimozide could have inhibited.

Androgenized female rats were used specifically to study the tonic release of gonadotrophins as the ovulatory surge release of $\mathrm{LH}$ is believed to be abolished in these animals (for review, see Harris \& Campbell, 1966). In the absence of 
ovulation, the hypertrophy of the ovary must be dependent on the tonic secretion of FSH and presumably L.H. Arai \& Gorski (1968) have shown that implantation of FSH (but not $\mathrm{LH}$ ) into the hypothalamus inhibits compensatory ovarian hypertrophy in androgenized rats. The effects of drugs on such hypertrophy are, therefore, likely to be due largely to suppression of FSH secretion. The reduction in compensatory hypertrophy caused by pimozide in this context probably relates mainly to an effect on FSH, though the same animals showed some increase in pituitary LH content. The latter could be due to inhibition of tonic LH secretion.

Apart from the results in androgenized females, the only evidence from the present investigation to suggest inhibition of FSH secretion was that pimozide increased pituitary stores of this hormone in one group of maturing males. Previous studies (Choudhury et al., 1973) have, however, provided other evidence that dopamine is involved in FSH secretion. The lack of effect of pimozide on the accumulation of FSH in androgen-treated castrates suggests that the drug has no marked inhibitory effect on FSH synthesis (Brown \& Fawke, 1972).

\section{ACKNOWLEDGMENTS}

We are grateful to Dr M. Hartog, Dr M. Ellwood and Dr. M. Shahmanesh for advice and assistance with the radioimmunoassay, for which materials were generously provided by the NIAMD, U.S.A., through Dr A. F. Parlow. Pimozide was donated by Mr John W. Pope of Janssen Pharmaceuticals.

\section{REFERENCES}

Andén, N. E., Butcher, S. G., Corrodi, H., Fuxe, K. \& Ungerstedt, U. (1970) Receptor activity and turnover rate of dopamine and noradrenaline after neuroleptics. Eur. Fnl Pharmac. $11,303$.

ARAI, Y. \& GoRskI, R. A. (1968) Inhibition of ovarian compensatory hypertrophy by hypothalamic implantation of gonadotrophin in androgen-sterilized rats: evidence for "internal" feedback. Endocrinology, 82, 871 .

Brown, P. S. (1971) Pituitary follicle-stimulating hormone in immature female rats treated with drugs that inhibit the synthesis or antagonise the actions of catecholamines and 5-hydroxytryptamine. Neuroendocrinology, 7, 183.

Brown, P. S. \& FAwKe, L. (1972) Effects of reserpine, p-chlorophenylalanine, $\alpha$-methyltyrosine, thymoxamine or methallibure on pituitary FSH in male rats. $\mathcal{7}$. Reprod. Fert. $28,167$.

Choudhury, S. A. R., Sharpe, R. M. \& Brown, P. S. (1973) Pituitary FSH activity in rats treated with apomorphine, pimozide and drugs that modify catecholamine levels. Neuroendocrinology, $12,272$.

FAwke, L. \& BROwn, P. S. (1970) Pituitary content of follicle-stimulating hormone in the female rat. 7. Reprod. Fert. 21, 303.

Harris, G. W. \& CAmprell, H. J. (1966) The regulation of the secretion of luteinizing hormone and ovulation. In The Pituitary Gland, vol. 2, p. 99. Eds. G. W. Harris and B. T. Donovan. Butterworths, London.

Hökfelt, T. \& FuXe, K. (1972) On the morphology and the neuroendocrine role of the hypothalamic catecholamine neurons. In Median Eminence: Structure and Function, p. 181. Eds. K. M. Knigge, D. E. Scott and A. Weindl. Karger, Basel.

Kordon, C. \& Glowinski, J. (1969) Selective inhibition of superovulation by blockade of dopamine synthesis during the critical period in the immature rat. Endocrinology, 85, 924.

McGann, S. M., Kalra, P. S., Donoso, A. O., Bishop, W., Schneider, H. P. G., Fawcetr, G. P. \& KRulich, I. (1972) The role of monoamines in the control of gonadotropin and prolactin secretion. In Median Eminence: Structure and Function, p. 224. Eds. K. M. Knigge, D. E. Scott and A. Weindl. Karger, Basel,

Steelman, S. L. \& Pohley, F. S. (1953) Assay of follicle stimulating hormone based on the augmentation with human chorionic gonadotrophin. Endocrinology, 53, 604. 